\title{
Editorial
}

Journal of Innate

Immunity

\section{From Starfish Oocytes to Inflammation: The Unforeseeable Destiny of Roscovitine in Cystic Fibrosis}

\author{
Véronique Witko-Sarsat \\ INSERM U1016, Institut Cochin, and CNRS-UMR 8104, Université Paris Descartes, Sorbonne Paris Cité, and Center of \\ Excellence, Labex Inflamex, Paris, France
}

Discoveries can take unpredictable paths! In a review presented in the current issue of the Journal of Innate Immunity, Meijer et al. [1] describe the rationale for evaluating roscovitine for the treatment of cystic fibrosis (CF) patients chronically infected with Pseudomonas aeruginosa. Roscovitine is a low-molecular-weight inhibitor of cyclin-dependent kinase (CDK) discovered over 20 years ago during studies on the regulation of cell division using a rather unlikely research subject, starfish oocytes [2]. Marine invertebrate oocytes and eggs have been used for decades to investigate cellular and molecular mechanisms involved in the regulation of the cell division cycle as these cells have a natural break at specific stages in the cell cycle [3]. In parallel to Xenopus oocytes and genetic models such as yeast and Drosophila, they have allowed the identification of the CDK1/cyclin B protein kinase as the major regulator in G2/M cell cycle transition. In fact, this discovery eventually led to the awarding of the Nobel Prize in Physiology or Medicine to Paul Nurse, Tim Hunt, and Leland H. Hartwell in 2001. CDK1/cyclin B is the archetype of CDKs that were found not only to be major players in all steps of the cell cycle but also to display other functions including a role in the central nervous system (CDK5/p25). Given that active CDK1/cyclin B is present in huge quantities in starfish M-phase oocytes, the group of Laurent Meijer at the CNRS (France) developed an af- finity chromatography purification method combined with a simple kinase assay to search for potential pharmacological inhibitors, and this led to the discovery of roscovitine in Roscoff [4]. This molecule has been used extensively as a pharmacological tool to investigate the cell cycle, synchronize cells, and trigger cell cycle arrest or apoptosis, in order to evaluate its effects on numerous diseases ranging from cancers, viral infections, or neurodegeneration to polycystic kidney disease.

While originally roscovitine was believed to exert its effects mainly on proliferating cells, Adriano Rossi and his colleagues (University of Edinburgh) reported that roscovitine also affected neutrophils, key cells in innate immunity deprived of proliferative capacities [5-10]. They discovered that roscovitine could trigger apoptosis of neutrophils, thereby favoring their phagocytosis by macrophages to promote the resolution of inflammation [11]. Notably, this activity was due to the inhibition of CDK7 and CDK9 involved in the regulation of RNA transcription [12]. These observations opened novel perspectives in the field of anti-inflammatory drugs and especially in chronic lung inflammation like that observed in CF patients.

CF is indeed a complex genetic disease [13] that involves the mutation of the chloride channel CFTR gene, where the deletion of F508 is the most frequent mutation.

\section{KARGER}

E-Mail karger@karger.com

www.karger.com/jin
(C) 2016 S. Karger AG, Basel

1662-811X/16/0084-0327\$39.50/0
Prof. Véronique Witko-Sarsat

INSERM U1016, Institut Cochin

27 rue du Faubourg Saint Jacques FR-75014 Paris (France)

E-Mail veronique.witko@inserm.fr 
This mutation leads to an incorrectly folded protein which is not appropriately localized to the plasma membrane channel, and this ultimately results in the manifestation of CF syndrome including thickening of the mucus within the airways and sustained chronic lung disease due to colonization by $P$. aeruginosa and sustained neutrophil-dominated inflammation [14].

As previously documented, the CFTR mutation seems to directly affect the function of cells from innate immunity. In neutrophils, the mutation in CFTR has been shown to affect phagosome formation [15]. In macrophages, the seminal discovery by Deborah J. Nelson (University of Chicago) of a high intraphagolysosomal $\mathrm{pH}$ within alveolar macrophages when CFTR was deficient [16] was the start of another unexpected finding. This high intraphagolysosomal $\mathrm{pH}$ prevents lysosomal proteases and lipases from digesting phagocytosed bacteria, and this may explain the high rate of bacterial infections in the lungs of CF patients. Roscovitine was tested for its potential effect on intraphagolysosomal $\mathrm{pH}$ and surprisingly restored the acidic ability of phagolysosomes to destroy bacteria, ultimately improving the bactericidal activity of CFTR-deficient alveolar macrophages [17]. However, this effect was not due to any correcting effect of roscovitine on F508del-CFTR since identical results were obtained in the complete absence of CFTR (cftr-/macrophages). Again, the effects of roscovitine were not associated with kinase inhibitory action as illustrated by the fact that the kinase-inactive roscovitine metabolite is active while the kinase-active (S)-isomer of roscovitine displays no intraphagolysosomal $\mathrm{pH}$-correcting ability.

The final unexpected twist that brought roscovitine in the $\mathrm{CF}$ field came from the discovery by the group of
Frédéric Beck (University of Poitiers) that roscovitine was displaying some corrector effect on F508del-CFTR [18]. Correcting mutated CFTR trafficking and intracellular localization constitutes one of the promising approaches to address CF treatment [19]. Very unpredictably, the correcting effect of roscovitine was found to be independent of its effects on protein kinases!

Safety studies of roscovitine have been carried out in healthy volunteers and cancer patients. Given the fact that roscovitine displays anti-inflammatory and analgesic properties and given the oral availability roscovitine, its distribution in the lung and its short-half life, it was tempting to repurpose this drug candidate for an evaluation in chronically infected CF patients [20]. Although roscovitine has many weaknesses, we can expect that the results of this initial clinical trial with this 'first-in-class' drug (at least as far as CF is concerned) will provide promising results that can provide orientation for either further optimization of roscovitine administration or the development of alternative, roscovitine-derived drug candidates.

It is ironic that over 30 years of work on the fundamental aspects of the marine invertebrate cell cycle and on kinase inhibition have ultimately led to a drug candidate acting on processes unrelated to cell division through a kinase-independent pathway on inflammatory cells that do not have any proliferation capacities! As a complex disease, CF might benefit from multifactorial therapeutic approaches, and it seems that roscovitine is endowed with multifaceted therapeutic power, which it might be useful to explore in other conditions where innate immunity is disturbed.

\section{References}

-1 Meijer L, Nelson D, Riazanski V, Gabdoulkhakova AG, Hery-Arnaud G, Leberre R, Loaëc N, Oumata N, Galons H, Nowak E, Gueganton L, Dorothée G, Prochazkova M, Hall B, Kulkarni AB, Gray RD, Rossi AG, Witko-Sarsat V, Norez C, Becq F, Ravel D, Mottier D, Rault G: Modulating innate and adaptive immunity by (R)-roscovitine: potential therapeutic opportunity in cystic fibrosis. J Innate Immun DOI: 10.1159/000444256.
$>2$ Meijer L, Borgne A, Mulner O, Chong JPJ, Blow JJ, Inagaki N, Inagaki M, Delcros JG, Moulinoux JP: Biochemical and cellular effects of roscovitine, a potent and selective inhibitor of the cyclin-dependent kinases cdc2, cdk2 and cdk5. Eur J Biochem 1997;243:527-536.

$>3$ Meijer L, Raymond E: Roscovitine and other purines as kinase inhibitors. From starfish oocytes to clinical trials. Acc Chem Res 2003;36: 417-425.

4 Rialet V, Meijer L: A new screening test for antimitotic compounds using the universal $\mathrm{M}$ phase-specific protein kinase, p34cdc2/cyclin Bcdc13, affinity-immobilized on p13suc1coated microtitration plates. Anticancer Res 1991;11:1581-1590.

\footnotetext{
5 Stenberg A, Karlsson A, Feuk-Lagerstedt E, Christenson K, Bylund J, Oldenborg A, Vesterlund L, Matozaki T, Sehlin J, Oldenborg PA: Signal regulatory protein alpha is present in several neutrophil granule populations and is rapidly mobilized to the cell surface to negatively fine-tune neutrophil accumulation in inflammation. J Innate Immun 2014;6:553-560.

-6 Sawant KV, Xu R, Cox R, Hawkins H, Sbrana E, Kolli D, Garofalo RP, Rajarathnam K: Chemokine cxcl1-mediated neutrophil trafficking in the lung: role of cxcr2 activation. J Innate Immun 2015;7:647-658.
} 
-7 Nani S, Fumagalli L, Sinha U, Kamen L, Scapini P, Berton G: Src family kinases and syk are required for neutrophil extracellular trap formation in response to beta-glucan particles. J Innate Immun 2015;7:59-73.

$\checkmark 8$ Herwald H, Egesten A: The neutrophil: a beautiful beast or a beastly beauty? J Innate Immun 2015;7:555-556.

-9 Lu T, Porter AR, Kennedy AD, Kobayashi SD, DeLeo FR: Phagocytosis and killing of Staphylococcus aureus by human neutrophils. J Innate Immun 2014;6:639-649.

10 Jovic S, Shikhagaie M, Morgelin M, Kjellstrom S, Erjefalt J, Olin AI, Frick IM, Egesten A: Expression of mig/cxcl9 in cystic fibrosis and modulation of its activities by elastase of Pseudomonas aeruginosa. J Innate Immun 2014;6:846-859.

11 Rossi AG, Sawatzky DA, Walker A, Ward C, Sheldrake TA, Riley NA, Caldicott A, Martinez-Losa M, Walker TR, Duffin R, Gray M, Crescenzi E, Martin MC, Brady HJ, Savill JS, Dransfield I, Haslett C: Cyclin-dependent kinase inhibitors enhance the resolution of inflammation by promoting inflammatory cell apoptosis. Nat Med 2006;12:1056-1064.
2 Leitch AE, Lucas CD, Marwick JA, Duffin R, Haslett C, Rossi AG: Cyclin-dependent kinases 7 and 9 specifically regulate neutrophil transcription and their inhibition drives apoptosis to promote resolution of inflammation. Cell Death Differ 2012;19:1950-1961.

13 Moriceau S, Lenoir G, Witko-Sarsat V: In cystic fibrosis homozygotes and heterozygotes, neutrophil apoptosis is delayed and modulated by diamide or roscovitine: evidence for an innate neutrophil disturbance. J Innate Immun 2010;2:260-266.

14 Witko-Sarsat V: Neutrophils in the innate immunity conundrum of cystic fibrosis: a CFTRrelated matter? J Innate Immun 2013;5:195196.

15 Zhou Y, Song K, Painter RG, Aiken M, Reiser J, Stanton BA, Nauseef WM, Wang G: Cystic fibrosis transmembrane conductance regulator recruitment to phagosomes in neutrophils. J Innate Immun 2013;5:219-230.

16 Di A, Brown ME, Deriy LV, Li C, Szeto FL, Chen Y, Huang P, Tong J, Naren AP, Bindokas V, Palfrey HC, Nelson DJ: CFTR regulates phagosome acidification in macrophages and alters bactericidal activity. Nat Cell Biol 2006; 8:933-944.
17 Riazanski V, Gabdulkhakova AG, Boynton LS, Eguchi RR, Deriy LV, Hogarth DK, Loaëc $\mathrm{N}$, Oumata $\mathrm{N}$, Galons $\mathrm{H}$, Brown $\mathrm{ME}$, Shevchenko P, Gallan AJ, Yoo SG, Naren AP, Villereal ML, Beacham DW, Bindokas VP, Birnbaumer L, Meijer L, Nelson DJ: TRPC6 channel translocation into phagosomal membrane augments phagosomal function. Proc Natl Acad Sci USA 2015;112:E6486-E6495.

18 Norez C, Vandebrouck C, Bertrand J, Noel S, Durieu E, Oumata N, Galons H, Antigny F, Chatelier A, Bois P, Meijer L, Becq F: Roscovitine is a proteostasis regulator that corrects the trafficking defect of F508del-CFTR by a CDK-independent mechanism. Br J Pharmacol 2014;171:4831-4849.

19 Bell SC, De Boeck K, Amaral MD: New pharmacological approaches for cystic fibrosis: promises, progress, pitfalls. Pharmacol Ther 2015;145:19-34.

20 Evaluation of (R)-roscovitine safety and effects in subjects with cystic fibrosis, homozygous for the F508del-CFTR mutation (ROSCO-CF). https://clinicaltrials.gov/ct2/show/ NCT02649751?term=roscovitine\&rank=1. 